\title{
Planning and Suitability Assessment of Large-scale Nature-based Solutions for Flood-risk Reduction
}

\author{
Adam Mubeen ${ }^{1}$ (D) $\cdot$ Laddaporn Ruangpan ${ }^{1,2}$ (D) Zoran Vojinovic ${ }^{1,3,4}$. \\ Arlex Sanchez Torrez ${ }^{1}$ (D) Jasna Plavšić ${ }^{3}$ (D)
}

Received: 29 September 2020 / Accepted: 4 May 2021/ Published online: 10 July 2021

(C) The Author(s) 2021

\begin{abstract}
Adverse effects of climate change are increasing around the world and the floods are posing significant challenges for water managers. With climate projections showing increased risks of storms and extreme precipitation, the use of traditional measures alone is no longer an option. Nature-Based Solutions (NBS) offer a suitable alternative to reduce the risk of flooding and provide multiple benefits. However, planning such interventions requires careful consideration of various factors and local contexts. The present paper provides contribution in this direction and it proposes a methodology for allocation of large-scale NBS using suitability mapping. The methodology was implemented within the toolboxes of ESRI ArcMap software in order to map suitability for four types of NBS interventions: floodplain restoration, detention basins, retention ponds, and river widening. The toolboxes developed were applied to the case study area in Serbia, i.e., the Tamnava River basin. Flood maps were used to determine the volume of floodwater that needs to be stored for reducing flood risk in the basin and subsequent downstream areas. The suitability maps produced indicate the potential of the new methodology and its application as a decision-support tool for selection and allocation of large-scale NBS.
\end{abstract}

Keywords Climate change $\cdot$ Nature-based solutions $\cdot$ Suitability mapping $\cdot$ Flood risk reduction

Adam Mubeen

adammubeen@live.com

1 Department of Water Supply, Sanitation and Environmental Engineering, IHE Delft Institute for Water Education, Delft, The Netherlands

2 Department of Hydraulic Engineering, Faculty of Civil Engineering and Geosciences, Delft University of Technology, Delft, The Netherlands

3 Faculty of Civil Engineering, University of Belgrade, Belgrade, Serbia

4 College of Engineering, Mathematics and Physics, University of Exeter, Exeter EX4 4QF, UK 


\section{Introduction}

The risk of adverse effects of climate change, and subsequent impact of hydro-meteorological hazards is increasing all over the world (Füssel et al. 2012; Lehner et al. 2006; EEA 2017). Consequently, flooding is considered a critical risk that needs to be addressed, due to significant impact on human life, the environment and the economy (IPCC 2014).

Conventional mitigation measures include 'grey' infrastructure (e.g., concrete structures, underground drain pipes, pumping stations) that do not easily adapt to future uncertainties such as climate change. Measures that employ natural processes, namely Nature-Based Solutions (NBS), are (in general) more adaptive (Voskamp and Van de Ven 2015; Faivre et al. 2018; Kuller et al. 2019). Moreover, they provide multiple benefits by restoring ecosystems, and providing opportunities for improving human well-being and biodiversity, as well as positive economic change (Cohen-Shacham et al. 2016; Debele et al. 2019; Jerzy et al. 2020). NBS exist in a variety of scales; small urban or local scales (e.g., bioretention cells, green roofs, and constructed wetlands), to large-scale measures applied across river basins, at a regional scale (e.g., floodplain restoration, reforestation, and making room for water bodies) (Ruangpan et al. 2020). Alves et al., (2019a) and Alves et al., (2019b) addresses concerns regarding trade-offs between different benefits and co-benefits of NBS and provided evidence that assessment of flood reduction measures can be significantly different when the co-benefits are not included in the analysis.

To advance adoption of NBS, there is a demand for methods to select, evaluate, and design NBS (European Commission 2015; Kuller et al. 2017; Maes and Jacobs 2017; Ruangpan et al. 2020). These methods can provide guidance for planners and decision-makers to select the most appropriate NBS for a project location of their interest (Backhaus and Fryd 2012; Lee et al. 2012). One of the first steps toward identifying, planning and implementing NBS in river landscapes, is to obtain knowledge of NBS in terms of spatial suitability (Guerrero et al. 2018). Hence, spatial analysis using geographic information systems (GIS) can be an effective tool to define a suitable location for NBS.

Suitability mapping has been established as a powerful spatial decision support tool (Demesouka et al. 2013), and is becoming the standard for spatial decision support (Malczewski and Rinner 2015). Several tools exist for assessing spatial allocation for NBS, for example, the Spatial Suitability ANalysis Tool (SSANTO - Kuller et al. 2019); Adaptation Support Tool (AST - Voskamp and Van de Ven 2015; van de Ven et al. 2016); Green Infrastructure Spatial Planning (GISP - Meerow and Newell 2017); and BMP siting tool (EPA 2018). However, these tools are limited in their applicability as they: (i) have only been applied to small scale NBS, (ii) are not available for users (e.g., SSANTO), and (iii) are not compatible with more recent versions of common GIS platforms such as ArcMap (e.g., BMP siting tool). This shows that there is a definite need for planning and suitability assessment of large-scale NBS.

This paper focuses on four common NBS for river basins: floodplain restoration, detention basins, retention ponds, and river widening. These measures have proved to be very effective in reducing flood risk in river basins. The objectives of this paper are: (i) to define criteria (based on a literature review) for the spatial allocation of NBS, (ii) to develop a methodology and tool for the spatial suitability assessment of NBS by integrating the previously defined criteria into a GIS approach, (iii) to test and verify the methodology and tool on an existing case study (Tamnava river basin in Serbia). 


\section{Review of Existing Tools for Spatial allocation of NBS}

A literature review was carried out to identify and evaluate existing tools that can be used for spatial allocation of NBS. The identification process is carried with the Scopus database to search for peer-reviewed articles published in scientific journals using titles, abstracts, and keywords using advanced search terms to include common and alternative terminology for NBS.

The search for planning, spatial allocation, and suitability tools for NBS using Scopus based on titles, abstracts and keywords lead to 444 articles (106 open access, 338 other). Based on abstracts this was narrowed down to 39 articles regarding tools, frameworks, methods, and models for planning and spatial allocation of NBS. Full review of these articles leads to 7 tools, models, and methods that can explicitly be used for mapping NBS.

The tools were assessed based on their requirements, NBS applied, input data and type, analysis methods, output type, and their applicability and limitations, particularly whether these tools can be used for spatial allocation of large-scale NBS. This information is used to establish the applicability of the tools in the allocation of large-scale NBS. The review is summarised in Table 1.

UrbanBEATS and SUDSLoc are both standalone software. While UrbanBEATS does not have a GIS based interface, GIS tools are still necessary for preparation of input, and for reading the output files. BMP siting tool and SSANTO are add-ons to ESRI ArcMap. HSA, HLU, and OM are methods that can be used on any mainstream GIS software.

GIS multi-criteria analysis (MCA) using local site conditions such as slope, streams characteristics, land use, etc. is employed in varying degrees by all tools, as a method for analysing suitability. It was found that nearly all the tools use similar inputs, including DEM, land use, soil type, imperviousness, groundwater depth, and stream characteristics.

It was found that most of these tools (SUDSLoc, UrbanBEATS, BMP siting tool, OM and SSANTO) are limited to urban catchments and small-scale NBS. While HSA and HLU can be utilised over larger catchments and large-scale NBS, these tools are highly dependent on specific data: soil conductivity, and floodplain state, respectively. Additionally, HLU is limited to only floodplain-based measures. This review shows that existing tools are not sufficient for the purpose of spatial allocation of large-scale NBS. Therefore, development of new methods and tools for mapping large-scale NBS would prove to be a valuable for supporting decision making in the allocation of NBS.

\section{Methodology for Mapping Spatial Suitability of Large-scale NBS}

While it has been established that the tools reviewed cannot be used for this exercise, the methods and criteria used for determining suitability of NBS in these tools have a good potential for use in allocation of large-scale NBS. A novel method and tools for mapping suitability of four large-scale NBS: floodplain restoration, detention basin, retention pond, and river widening are developed by: (1) determining criteria for spatial allocation of NBS; (2) development of a conceptual model; (3) development of toolboxes for spatial allocation of large-scale NBS; and (4) applying the toolboxes in a RECONECT study area. 


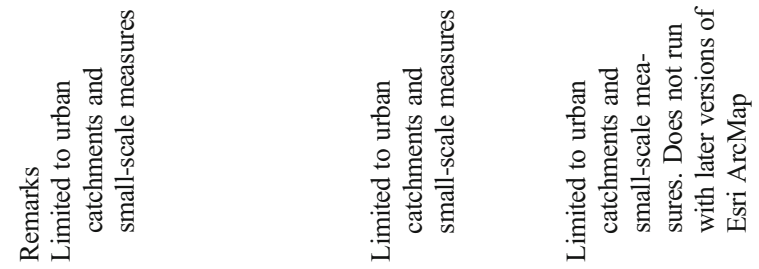

言零

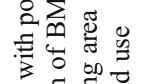

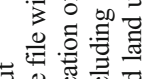

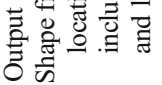

敦

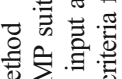

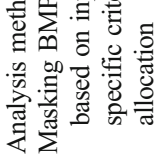

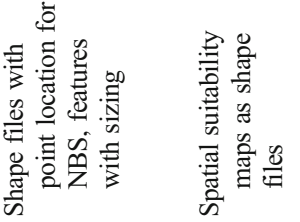

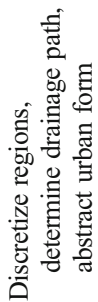

छ.

웅. 월

믈 章

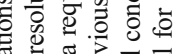

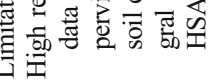

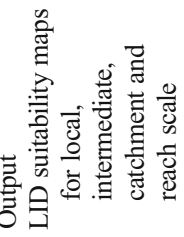

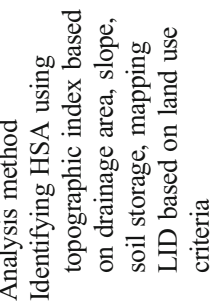

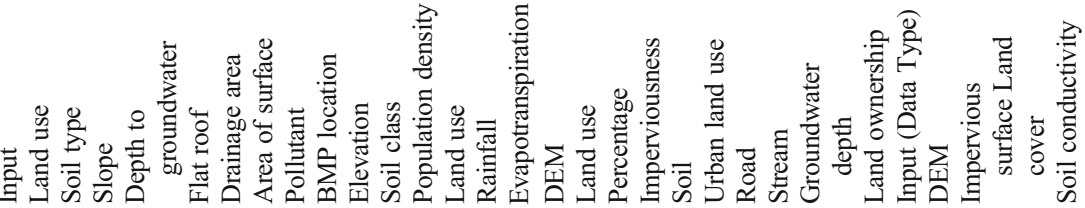

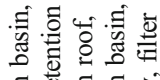

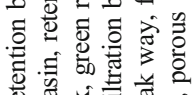

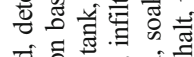

焉鄗

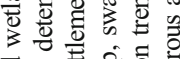

尊

๘

๖

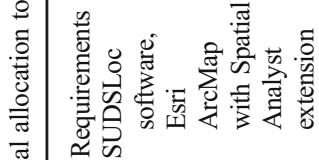

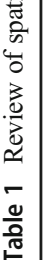

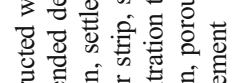

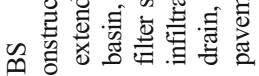

ż

竎

हैำ

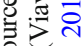

跑

焉

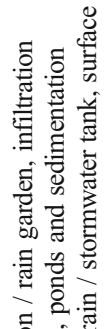

뜬.

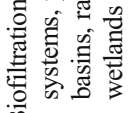

웅

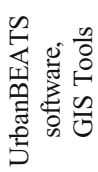

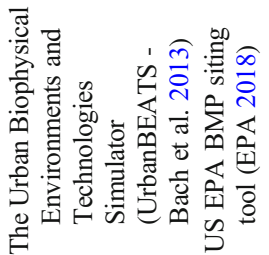

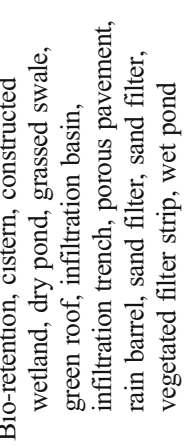

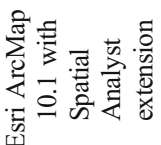

总
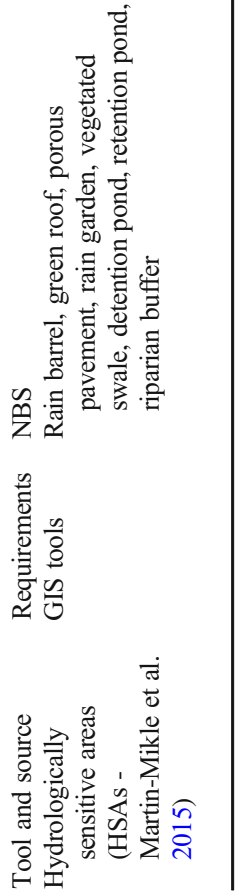


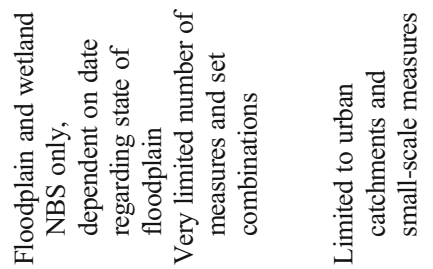

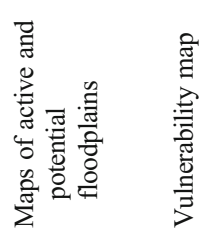

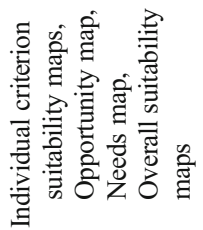

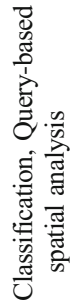

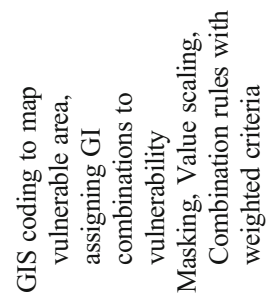

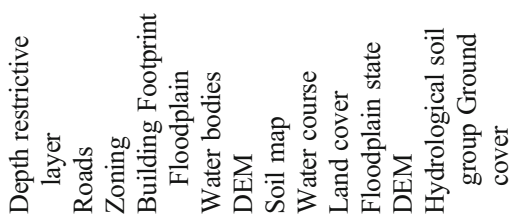

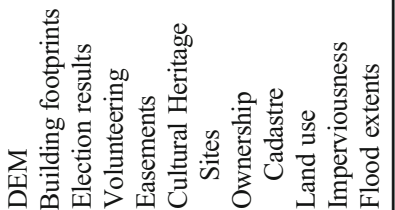
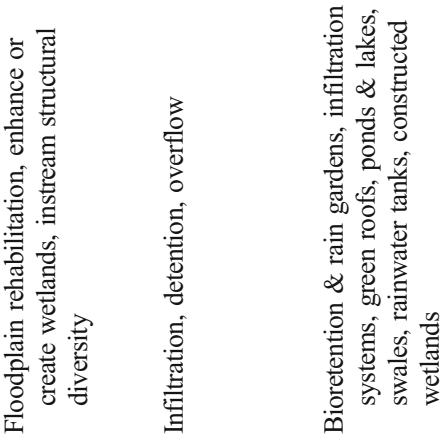

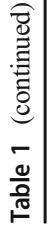

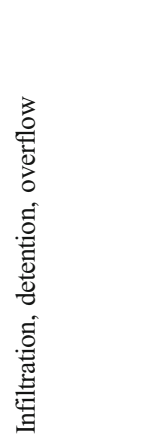

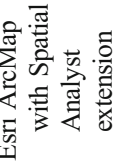

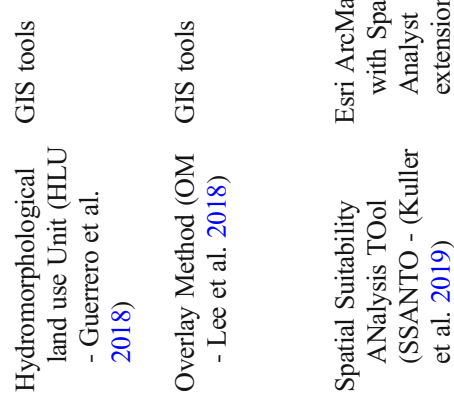




\subsection{Determination of Criteria for Spatial Allocation of NBS}

The general criteria were determined by further analysing the seven tools in the literature review. Based on this analysis, the criteria include site conditions, catchment characteristics such as topography, streams, and water bodies, land use and land cover, roads and infrastructure, and performance requirements such as risk reduction and water management (Table 2). To reduce overlap and repetition of the criteria, they are divided into three distinct and broad categories: (1) Biophysical (natural aspects of the landscape including topography, hydrology, soil, water bodies, etc.); (2) Planning and governance (different types land use such as agriculture, industry, etc.), urban fabric, and infrastructure); and (3) Performance Requirements (service requirements such as reduction of natural hazards, water management, etc.).

In addition to utilising similar input data, the tools also use similar criteria to determine site suitability for NBS. Based on the score, the most commonly used criteria for spatial allocation of NBS in the analysed tools, with a score $\geq 4$ (for a simple majority of tools analysed), are slope, soil type/class, imperviousness, distance from stream, land use type/zone, urban land use and road buffer. Imperviousness is directly related to changes in land use (Federal Interagency Stream Restoration Working Group (FISRWG) 1998), and urban land use can be characterised as land use type over larger scales, these two criteria can be represented in land use type/zone.

Table 2 Criteria used for spatial allocation tools of NBS

\begin{tabular}{|c|c|c|c|c|c|c|c|c|c|}
\hline \multirow[t]{2}{*}{ Categories } & \multirow[t]{2}{*}{ Criteria } & \multicolumn{7}{|l|}{ Tools } & \multirow[t]{2}{*}{ Score } \\
\hline & & SUDSLoc & UrbanBEATS & $\begin{array}{l}\text { BMP } \\
\text { Siting } \\
\text { tool }\end{array}$ & HSA & HLU & $\mathrm{OM}$ & SSANTO & \\
\hline \multirow[t]{9}{*}{ Biophysical } & Slope & $\checkmark$ & $\checkmark$ & $\checkmark$ & $\checkmark$ & $\checkmark$ & $\checkmark$ & $\checkmark$ & 7 \\
\hline & Flow path & & $\checkmark$ & & & & $\checkmark$ & & 2 \\
\hline & Drainage area & $\checkmark$ & & $\checkmark$ & $\checkmark$ & & & & 3 \\
\hline & Soil type/class & $\checkmark$ & $\checkmark$ & $\checkmark$ & & $\checkmark$ & $\checkmark$ & & 5 \\
\hline & $\begin{array}{l}\text { Soil } \\
\text { conductivity }\end{array}$ & & & & $\checkmark$ & & & & 1 \\
\hline & $\begin{array}{l}\text { Depth to } \\
\text { groundwater }\end{array}$ & $\checkmark$ & & $\checkmark$ & $\checkmark$ & & & & 3 \\
\hline & Imperviousness & & $\checkmark$ & $\checkmark$ & $\checkmark$ & & $\checkmark$ & & 4 \\
\hline & $\begin{array}{l}\text { Distance from } \\
\text { stream }\end{array}$ & $\checkmark$ & & $\checkmark$ & $\checkmark$ & $\checkmark$ & & $\checkmark$ & 5 \\
\hline & Water bodies & $\checkmark$ & & & $\checkmark$ & & & & 2 \\
\hline \multirow[t]{3}{*}{$\begin{array}{l}\text { Planning and } \\
\text { governance }\end{array}$} & $\begin{array}{l}\text { Land use } \\
\text { type/zone }\end{array}$ & $\checkmark$ & $\checkmark$ & & $\checkmark$ & $\checkmark$ & $\checkmark$ & $\checkmark$ & 6 \\
\hline & Urban land use & $\checkmark$ & $\checkmark$ & $\checkmark$ & $\checkmark$ & & $\checkmark$ & $\checkmark$ & 6 \\
\hline & Road buffer & $\checkmark$ & $\checkmark$ & $\checkmark$ & $\checkmark$ & & & & 4 \\
\hline \multirow{3}{*}{$\begin{array}{l}\text { Performance } \\
\text { require- } \\
\text { ments }\end{array}$} & $\begin{array}{l}\text { Floodplain } \\
\text { state }\end{array}$ & & & & & $\checkmark$ & & & 1 \\
\hline & Flood hazard & & & & & & & $\checkmark$ & 1 \\
\hline & $\begin{array}{l}\text { Water } \\
\text { management }\end{array}$ & & $\checkmark$ & & & & & & 1 \\
\hline
\end{tabular}


Slope, soil type/class, distance from stream, land use type/zone, and road buffer are used as general criteria for spatial allocation of large-scale NBS as existing tools demonstrated their applicability for spatial allocation over different catchment scales and a range of NBS.

\subsection{Conceptual Model}

Using the general criteria required for spatial allocation as slope, soil type/class, distance from stream, land use type/zone, and road buffer, a conceptual model (Fig. 1) is developed to illustrate the input and processes needed to produce a suitability map as an output. The base maps needed for the model, i.e., input data, are defined by each criterion. The slope can be derived from a digital elevation model (DEM), soil class/type can be produced using soil maps, distance from stream can be estimated using maps of the streams and rivers, land use type/zones can be determined from land use and land cover maps, and road buffers can be determined using maps of road infrastructure.

The derived maps are transformed using conditions for each criterion to produce maps which show areas where each condition is met. These maps are then combined to produce a

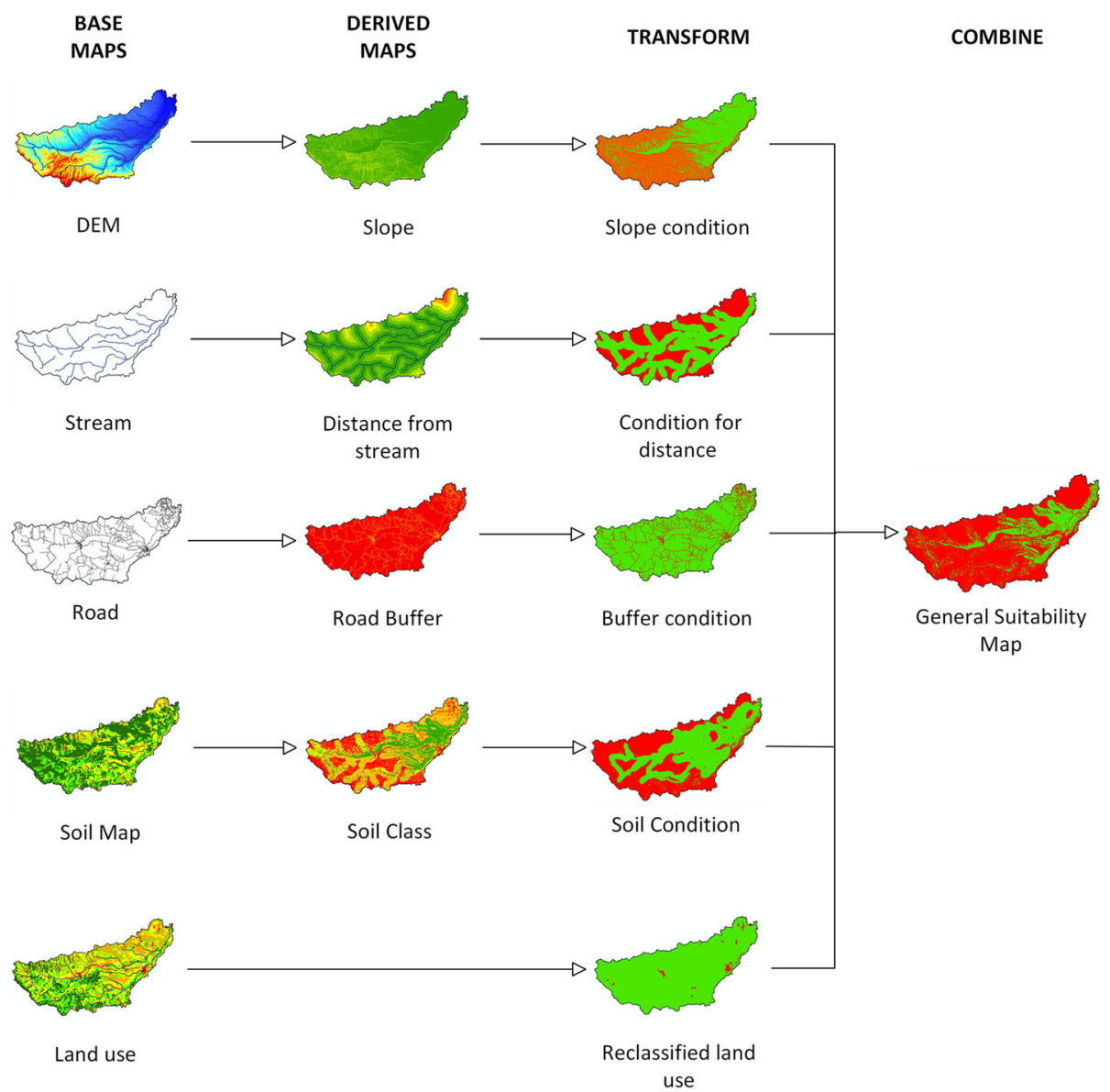

Fig. 1 Conceptual model for mapping suitability for NBS 
general suitability map that delineate areas where all base conditions or general criteria are map. The general suitability map is coupled with NBS specific criteria to create maps that show suitability for each NBS.

\subsection{Setting Up Toolboxes for Mapping Suitability}

The conceptual model (Fig. 1) is utilised to create a toolbox in ESRI ArcMap 10.5, its model builder, and spatial analysis tools. ArcMap provides a powerful GIS interface where the conceptual model can be implemented using tools that can be used for a variety of functions including determining hydrological characteristics in a catchment, raster calculations, interpolation, and estimation of areas and volumes. The conceptual model is utilised to define the base maps i.e., input data needed for the model and the processes used to derive, transform, and combine GIS data to produce suitability maps.

Base maps are used to derive maps using slope and Euclidean distance (i.e., the shortest distance between two points) calculations for slope rate and distance from rivers and roads, respectively. The derived maps are raster images conforming to resolution of the input DEM, which are then transformed to Boolean maps to show areas that meet the conditions; (1) slope rate $\leq 5 \%$, (2) distance from river $\leq 1 \mathrm{~km}$, and (3) distance from for $\geq 50 \mathrm{~m}$. The land use map is reclassified to a Boolean scale, to distinguish between areas that are permeable to land use change (e.g., agricultural land, parks, natural land) and those impermeable to land use change (e.g., urban areas, industrial zones). Utilising a Boolean scale allows combination of several layers using simple logic operations as all derived maps are on the same simplified scale. The transformed Boolean raster maps are converted to vector layers and a geometric intersection of all the four layers is computed to produce discrete polygons that show areas in the watershed where all the spatial allocation criteria are met. This produces the general suitability map of the methodology that is used as general criteria for spatial allocation.

The general suitability map is combined with measure specific criteria, which are dependent on the type of NBS, to locate regions where these measures can be applied. The Flow length tool is used to produce a raster of upstream and downstream distance, along the flow path of the catchment. This is divided into three sections to delineate upstream, midstream, and downstream sections of the catchment along the river for determining areas best suited for floodplain restoration, detention basins, and retention ponds. A buffer zone from the banks of the river is similarly used as a measure-specific criterion for river widening.

The suitability map for each NBS consists of vector layers consisting of polygons for floodplain restoration, retention pond/detention basin and lines for river widening, which constitute the output of the tools.

\subsection{Verification of Approach for Mapping Suitability}

The methodology only maps suitability and does not select and size specific locations for the NBS. In lieu of hydrological and hydraulic models, the suitability maps produced are assessed using two approaches:

1. Comparing suitability maps with satellite or digital images, using Google Earth Pro, to identify areas where the suitability may not match the actual or existing conditions of the study area. The suitability maps are laid over digital images of the area to identify where produced suitability maps may encroach on urban areas and other spaces that are not permeable for land use change; 
2. Flood maps and suitability maps are utilised to generate interpolated surfaces using the Inverse Distance Weighting (IDW) tool. The Surface difference tool in the 3D analyst tools is used to calculate displacement between the generated surfaces and the catchment surface (DEM) to estimate volume between the two surfaces. This gives an estimate of the volume of floodwater and the storage capacity available for the NBS. The suitability maps can be used to select NBS sites that have enough potential to store the estimated volume of floodwater.

\subsection{Case Study}

The case study area used to test the methodology is from the EC-funded H2020 RECONECT project, Tamnava River basin, in Serbia (Fig. 2). Tamnava River is a tributary of the Kolubara River; an $87 \mathrm{~km}$ long river that flows through western Serbia, which itself is a tributary to the river Sava. The Tamnava basin stretches over an area of $746 \mathrm{~km}^{2}$, and houses the rivers Tamnava and its main tributary Ub. The Tamnava River flows into the Kolubara River about $7 \mathrm{~km}$ south of the town of Obrenovac, lying on the confluence of the Kolubara River with the Sava River. The Kolubara basin houses considerable lignite reserves that supply approximately half of the national thermal energy. Lead, zinc, rare antimony, are some of the minerals mined in the region (Serbian Environmental Protection Agency (SEPA) 2014).

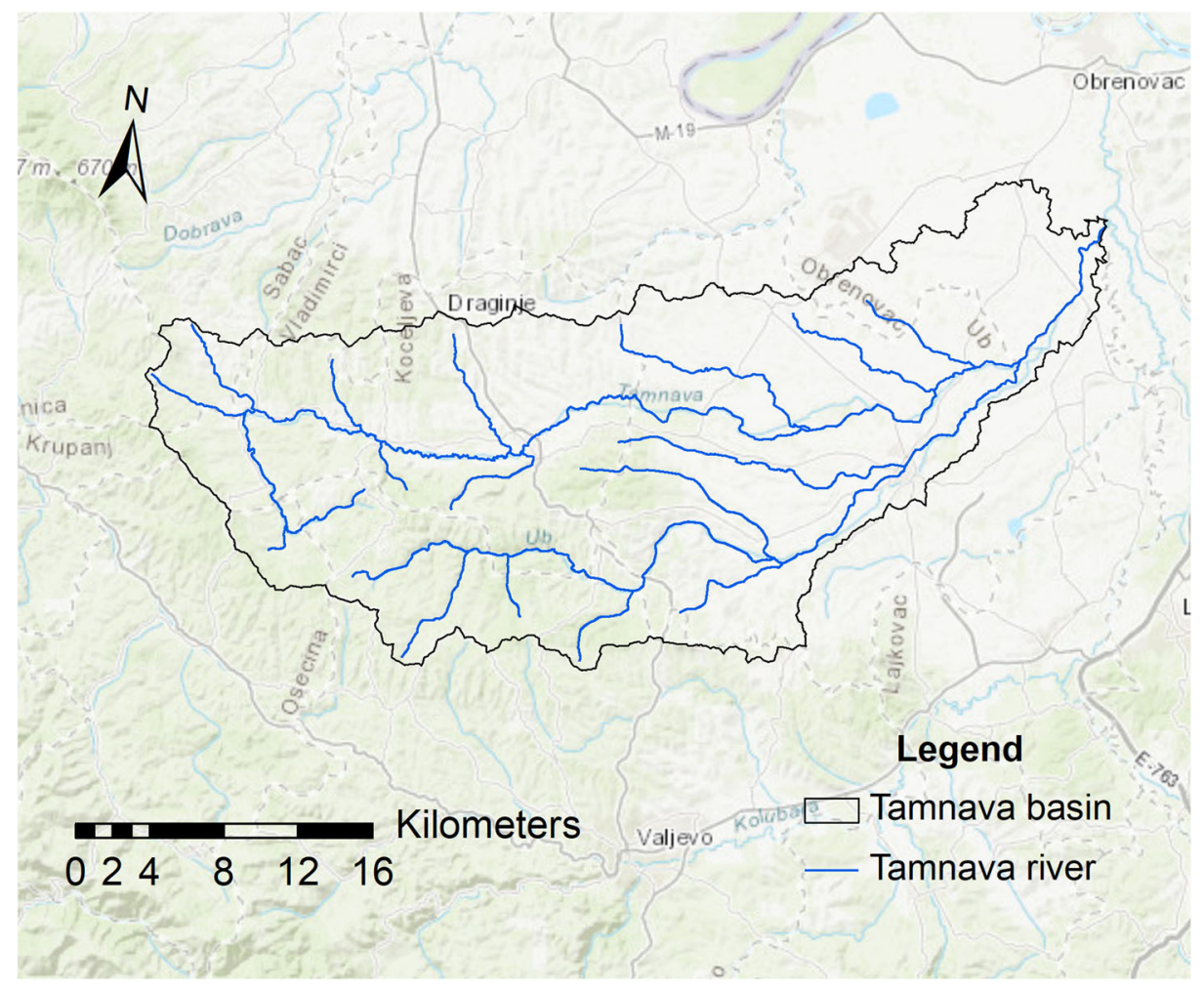

Fig. 2 The Tamnava River basin 
The Kolubara River basin's hydrological and geomorphological characteristics make the area susceptible to flood waves. The Tamnava River basin suffered from devastating floods in 1999, 2006, 2009, and 2014. Despite mitigation efforts, flooding continues to endanger lives, agriculture, infrastructure, and private and industrial properties in this area (Babić-Mladenović and Kolarov, 2016). In May 2014, record-breaking rainfall of more than $200 \mathrm{~mm}$ occurred over western Serbia within a week due to low-pressure system "Yvette". This rainfall equivalent of 3 months led to extensive flooding in urban and rural areas over whole Serbia, but especially in the Kolubara River basin (Plavšić et al. 2014). High intensity flash floods devastated houses, parts of the roads, and bridges, while the casualties were also reported. The overall estimated damage and losses exceeded EUR 1.5 billion (Government of the Republic of Serbia 2014).

\section{Results}

\subsection{General Suitability Map}

The toolbox was applied using input data for the Tamnava river basin to derive maps for the criteria defined in Section 3.3. The maps were transformed using the criteria and conditions to produce the criteria-based Boolean maps of the same scale which were converted to vector layers. The intersection of these layers was computed to produce the general suitability map as illustrated in Fig. 3 to show areas where all criteria are met.

As a result, $23.99 \%$ of the catchment area is shown to meet all 4 criteria. The general suitability map is used as a base for defining suitability different measures. This map is combined with NBS specific criteria described in Section 3.3 to determine the regions that are suitable for each type of NBS.

\subsection{Suitability Maps for NBS}

Suitability maps for each NBS were developed by combining general suitability map (Fig. 3) and the NBS specific criteria. Establishing storage using NBS such as detention basins and

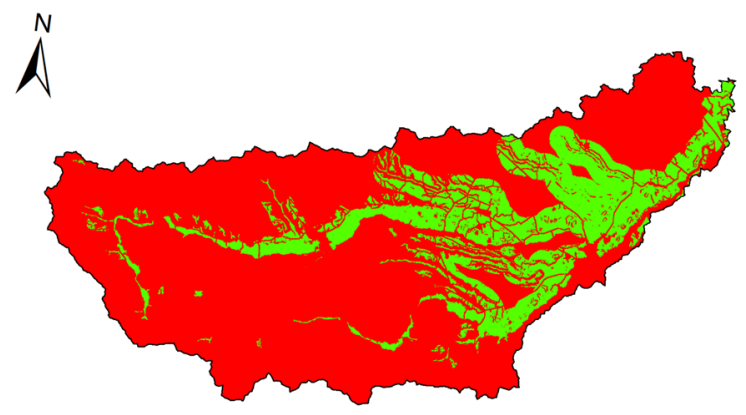

Legend

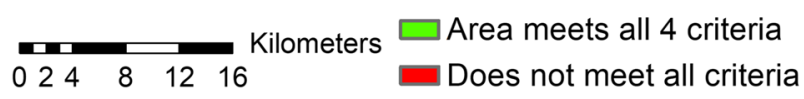

Fig. 3 General suitability map 
retention ponds in upstream areas of the catchment can help to reduce the amount of runoff that flows downstream. Floodplain restoration is more effective in flatter areas as it provides more area for conveyance. Since smaller isolated regions cannot provide enough storage volume for effective flood attenuation, regions with an area of less than 10 ha were removed from the suitability map.

Figure 4a shows 105 regions with a combined area of 14,860 ha ( $19.92 \%$ of catchment) were identified; shows 91 regions with a total area of 7723 ha (10.35\% of catchment) are considered as suitable locations for establishing detention basins and retention ponds as NBS, and 14 regions amounting to a total area of 7137 ha (9.57\% of catchment) that is suitable for floodplain restoration. Figure $4 \mathrm{~b}$ shows the areas along the river widening is possible on continuous stretches of the river length. These are areas where buffer areas exist along one or both banks of the river. Up to a $51.09 \mathrm{~km}$, including a continuous stretch of $5.36 \mathrm{~km}$, along the length of the Tamnava River was identified as suitable for widening.

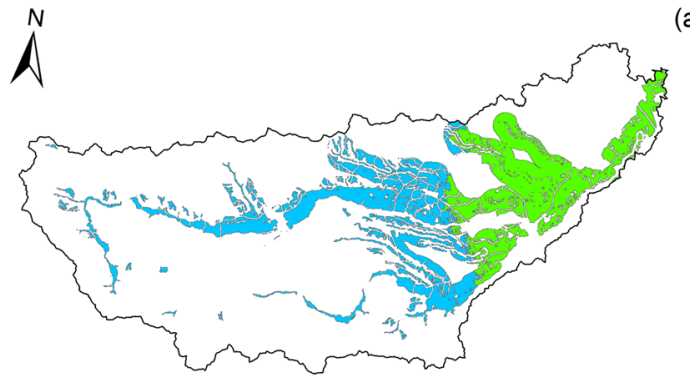

(a)

a)

\section{Legend}

Floodplain restoration

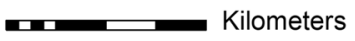

$024 \quad 8 \quad 12 \quad 16$ Detention basins or Retention ponds

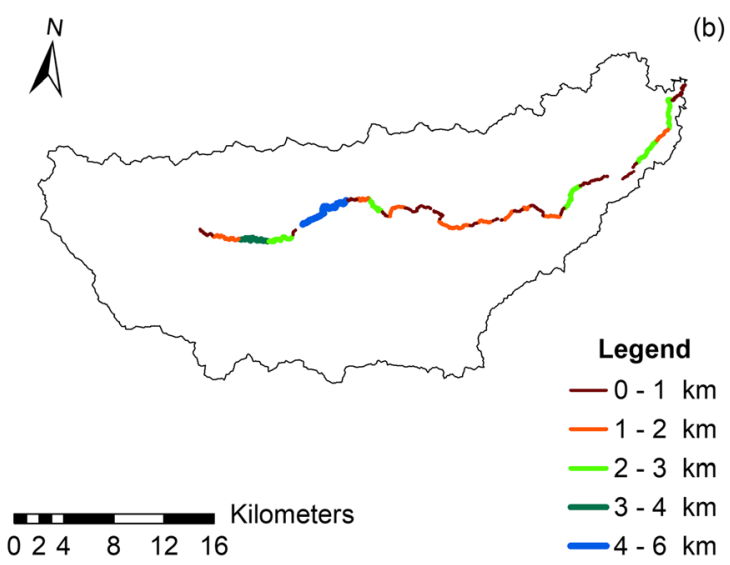

Fig. 4 Suitability maps for (a) floodplain restoration, detention basins, and retention ponds (b) river widening 


\subsection{Verification of Approach for Mapping Suitability}

\subsubsection{Comparison with Digital Images}

The polygons from the suitability maps were laid over digital images from Google Earth Pro to compare the suitability derived using the method with actual conditions in the study area. Each coloured polygon in Fig. 5 indicates a region that has been identified as suitable for NBS and the different colours indicate that the regions are not connected to each other. This shows that the suitable areas do not intersect with both of the main urban areas in the catchment, towns of Koceljeva (Fig. 5a) and Ub (Fig. 5b). The areas from the suitability maps also do not intersect with mineral extraction and mining activities, Northeast and East of Slatina (Fig. 5c) and Southwest of Donje Crniljevo (Fig. 5d). However, it can be seen that the areas overlap rural settlements (Fig. 5e). There is also a large area of over 3500 hectares, the area surrounding the villages Stubline, Trstenica, and Piroman, of relatively flat land (slope rate $<5 \%$ ), close to the downstream end of the catchment, that is not accounted for in the suitability mapping (Fig. $5 \mathrm{f}$ ).

Comparison of suitability maps with recent digital images show that the areas from the suitability maps areas do not intersect urban, industrial, and mining areas, but the areas overlap rural settlements. This shows that while urban areas and areas with mining activities are represented in the input used for land use, rural settlements are not included. Additionally, downstream areas with relatively flat land were not accounted for by the method.

\subsubsection{Estimating Volume of Floodwater and Storage Capacity Required}

For the second step in verification flood inundation area from the May 2014 flood event was used to produce a flood map and to determine the volume of floodwater. To estimate the volume, the vector layers derived from the flood map and NBS specific suitability maps were utilised to generate the surfaces illustrated in Fig. 6, using the IDW interpolation. This surface is compared with the DEM to determine the storage volume available under the polygons, considering a mean error of $-2.64 \mathrm{~m}$, with a standard deviation of $1.70 \mathrm{~m}$, Root Mean Square Error (RMSE) of $3.14 \mathrm{~m}$ at a $95 \%$ confidence level (EEA 2014) to account for the accuracy of the vertical component of the DEM.

The surfaces in Fig. 6 and the DEM were used to calculate the volumes of floodwater and storage capacity, using the Surface difference tool. An estimated flood volume of 4 to $8 \mathrm{Mm}^{3}$ was generated and floodplain restoration and detention basins/retention ponds were shown to provide a potential storage volume of 28 to $42 \mathrm{Mm}^{3}$ and 10 to $22 \mathrm{Mm}^{3}$, respectively. This shows that the suitability maps (Fig. 4) can be used to select areas to develop NBS that have adequate capacity to store the estimated volume of floodwater in the Tamnava basin from the May 2014 flood event. The additional storage potential can be utilised to prevent flooding further downstream in the Kolubara basin.

\section{Discussion}

This study shows that the methodology can be effectively used to map suitability for largescale NBS. The method can be easily implemented in a GIS environment, as demonstrated. There is potential for automation of this method using python since the toolbox has already been developed in ArcMap. This can minimize the need for data manipulation by the user. 


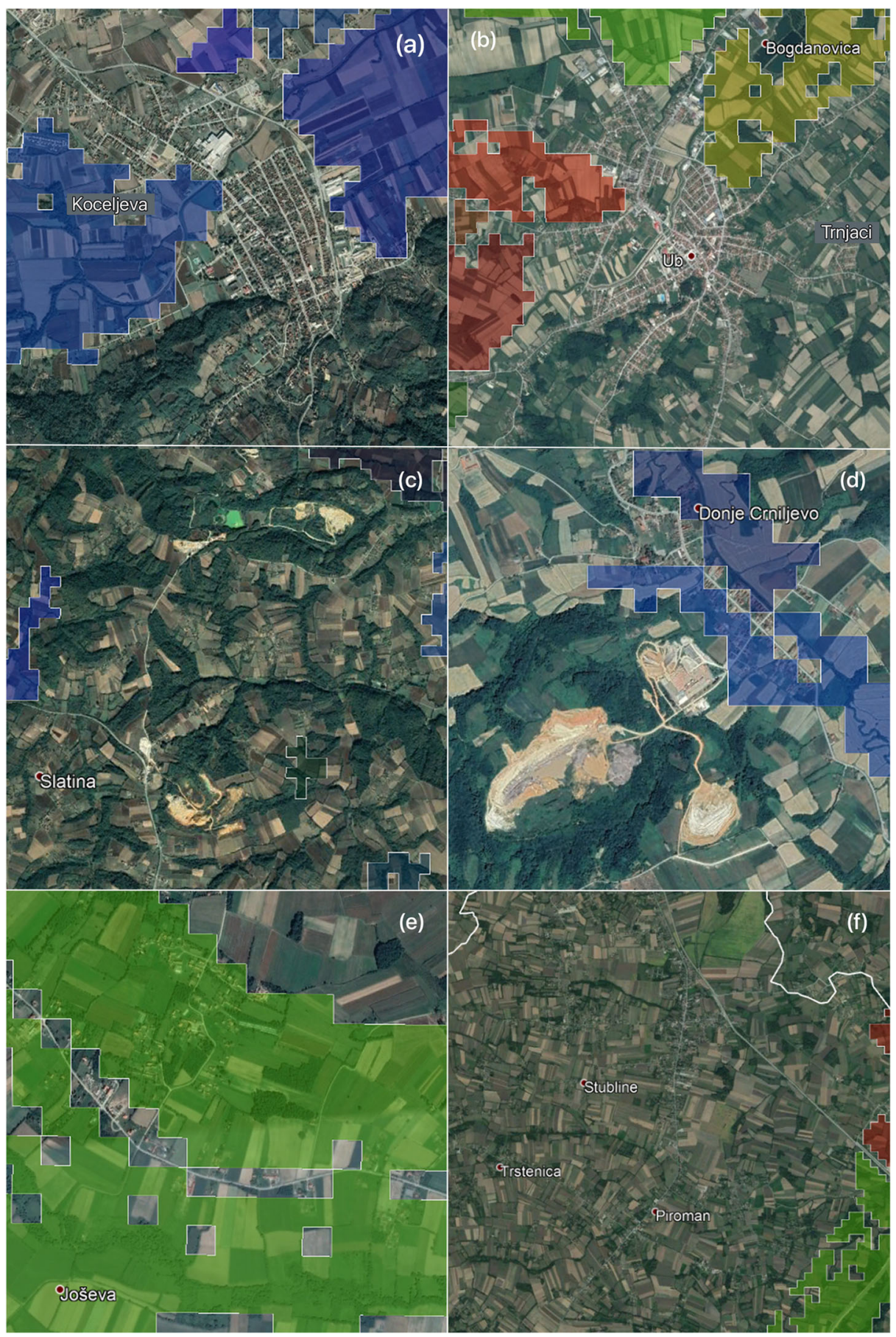

Fig. 5 Comparing NBS suitability with (a) Urban areas Koceljeva and (b) Ub, (c) mineral extraction and mining activities Northeast and East of Slatina and (d) Southwest of Donje Crniljevo, (e) Rural areas, and (f) Area not taken into account 


\section{$\Lambda$}

(a)
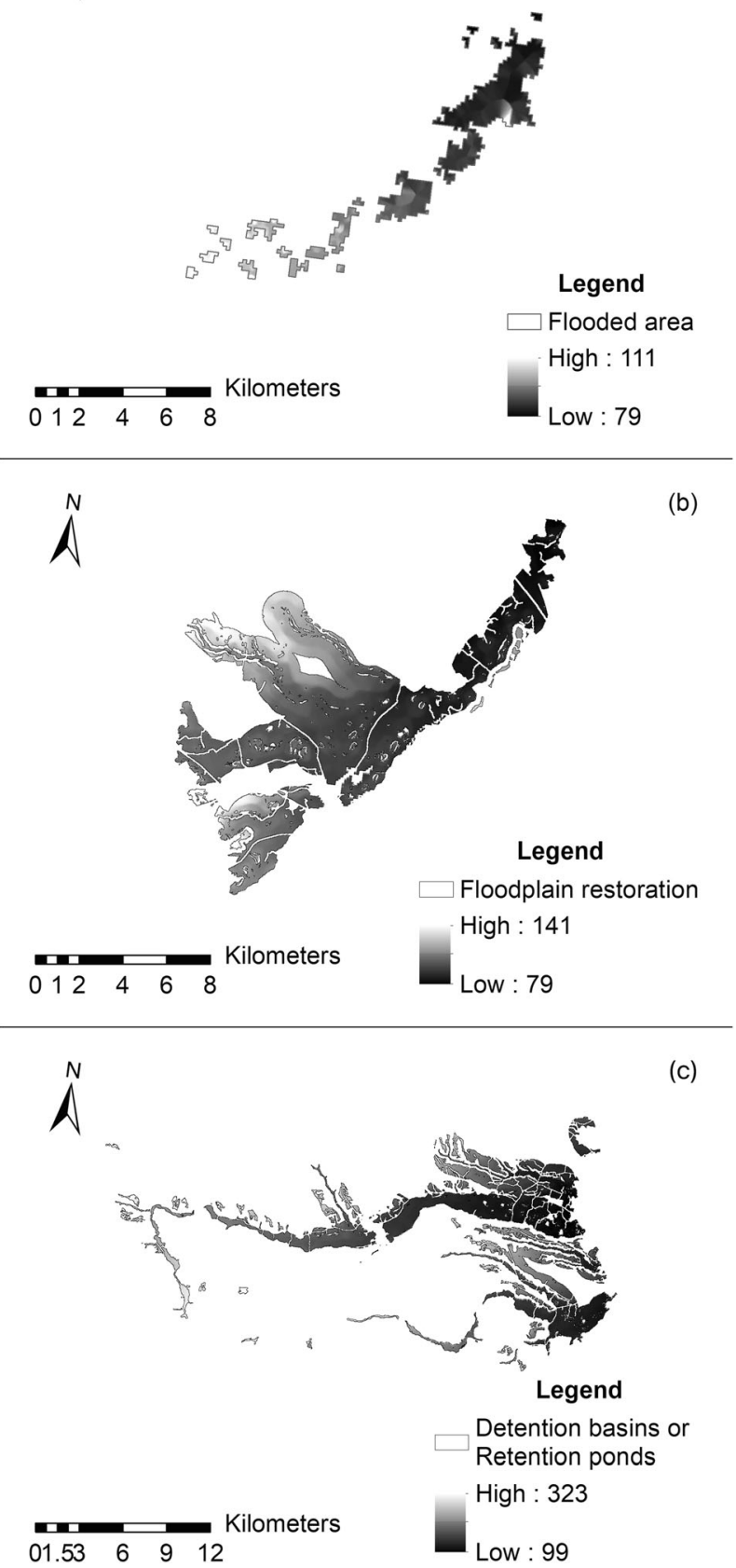

Fig. 6 IDW surface for (a) flooded areas, (b) floodplain restoration areas, and (c) detention basins

Following the 2014 flood, a number of measures for flood risk reduction in the Kolubara River basin were proposed (Babić-Mladenović and Kolarov 2016), including three detention 
reservoirs in the Tamnava basin. Comparison with the suitability map (Fig. 4) shows that these locations fall within the areas identified in the suitability map using this methodology. This shows that the methodology can successfully map suitability and that it can be used for spatial allocation of large-scale NBS.

To demonstrate the use of methodology in the decision-making process, in the study area, we can use the estimated flood volume of the May 2014 flood, and select areas from the suitability map (Fig. 4) are selected. The storage capacity within the area is calculated using the method outlined in Section 4.3.2. This gives a combined storage capacity of 10 to $16 \mathrm{Mm}^{3}$, which is more than adequate to cater for the estimated volume of floodwater. The NBS are assigned to these areas based on the suitability, and this completes the process of selection and allocation NBS to produce the map illustrated in Fig. 7. This indicates that the new methodology has potential to be utilised as a decision-support tool for selection and spatial allocation of large-scale NBS. The volumes estimated by this method is a very rough estimation as seen by the large range of volume for each NBS. The actual volume will depend upon subsequent planning steps, including the conceptual design and engineering design of the NBS at the selected sites.

A drawback of this method is that it is implemented in ArcMap using its spatial analyst toolset. While ArcMap is a standard software used for GIS applications, it is a proprietary software and needs to be purchased. However, the methodology itself can be applied over any open-source GIS tool that has functions for GIS-MCA. More input, such as soil and groundwater conditions, will be necessary to map other types of large-scale NBS.

Input data used for streams does not account for some downstream areas in the catchment. CLC, which was utilised for input as land use, does not account for rural settlements. This can be remedied by using locally produced maps for land use with better representation of settlements. Additional areas that are unaccounted for by the model and toolbox may have been caused by inaccuracies in the shape files used as input stream data. Natural waterways such as streams and rivers are usually delineated using flow conditions derived from DEM. However, modifications to the river such as river training works and the quality or the resolution of the DEM used for delineating waterways, can lead to these discrepancies. This may be remedied by comparing input data with maps of existing streams and rivers from other

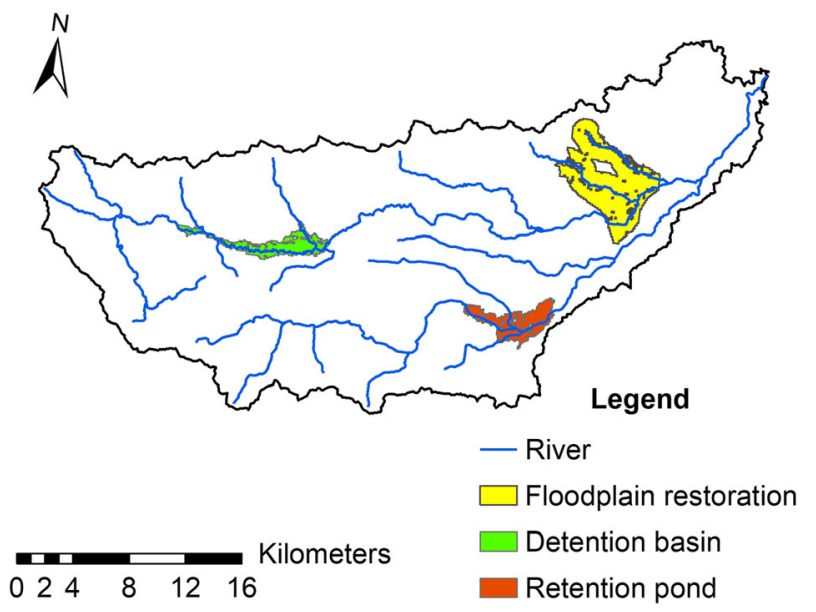

Fig. 7 Selection and allocation of NBS 
sources such as local governments. Therefore, the preparation of precise input data is imperative for effective use of this methodology. Moreover, the suitability maps produced for river widening cannot be validated without the use of a hydraulic model. Flood vulnerability maps may be used instead of flood maps from specific events, as these maps would delineate areas where interventions are needed more urgently. Sarkar and Mondal (2020) proposed a method for mapping vulnerability using frequency ratio (FR) model, that could be useful as a further step for allocation of NBS.

The methodology can be extended to include more large-scale NBS by adding more NBS specific criteria for allocation. Criteria can include soil class, depth of ground water table, and depth to bedrock. Input data such as DEMs and the shape files for streams needs to be compared with validated information from localities such as updated land survey information and maps to improve accuracy and coverage. The land use classification needs to include smaller settlements and other essential infrastructure. Where available, detailed land use maps must be used instead of CLC.

The methodology can be automated further by coding in python or other appropriate programming language to reduce the number of operations that needs to be carried out by users to produce suitability maps. Using open-source GIS environments such as QGIS can make the tools more available. Validation using more case studies and using hydrological and hydraulic models to evaluate the performance of NBS selected and allocated using this methodology as a subsequent step, can further improve the method.

\section{Conclusions}

The present paper describes a methodology and toolbox for mapping suitability of large-scale NBS for flood risk reduction in catchments, using GIS-MCA. The novel methodology incorporates criteria used for determining suitability of NBS in existing tools, which are inapplicable for large-scale NBS.

This research identified seven existing tools that can be used in selection and spatial allocation of NBS. These tools were analysed for their applicability in allocation of large scale NBS. The study found that these tools are limited to urban catchments in terms of the catchment type, limited to small-scale NBS, or highly specific to the context in which the tools were developed. It was established that these tools are not adequate for allocation of large-scale NBS.

The criteria used for determining suitability of NBS in these tools were used to develop a conceptual model for mapping suitability of large-scale NBS. This research proposes a methodology for spatial allocation of large-scale NBS that utilises the conceptual model for suitability mapping. The methodology was implemented in ESRI ArcMap software to produce a toolbox that consists of models that can be employed to map suitability for four large-scale NBS: floodplain restoration, detention basins, and river widening.

The toolbox developed was applied to the RECONECT case study area in Serbia, the Tamnava River basin, to produce suitability maps for the four NBS. Flood maps from May 2014 floods were used to determine the volume of floodwater that needs to be stored for reducing flood risk in the basin and subsequent downstream areas. The suitability maps were used to estimate the storage capacity available for NBS within the catchment and was used to demonstrate how the methodology can be used for selection and allocation of largescale NBS. 
The toolbox can be utilised to produce suitability maps for the four types of NBS. Flood maps can then be used to determine the volume of floodwater that needs to be stored for reducing flood risk in the basin and subsequent downstream areas. The suitability maps can then be used to identify areas where such a storage capacity is available for development of NBS within the catchment. The suitability maps produced using the methodology and toolboxes indicate the potential of the new methodology as a decision-support tool for selection and spatial allocation of large-scale NBS as such a tool does not currently exist for spatial allocation of large-scale NBS.

Acknowledgements Production of this article received funding from the European Union's Horizon 2020 Research and Innovation programme under grant agreement no. 776866 for the research project RECONECT (Regenerating ECOsystems with Nature-based solutions for hydro-meteorological risk rEduCTion). The article is based on a thesis titled "Supporting Decision Making in the Allocation of Nature-based Solutions for Flood Risk Reduction" produced for the partial fulfilment of requirements for the Master of Science degree at IHE Delft Institute for Water Education, Delft, the Netherlands.

Author Contributions M, LR, ZV and AS contributed to the study conception and design. Material preparation, data collection was performed by AM, LR and JP. Analysis was performed by AM and LR. The first draft of the manuscript was written by AM and all authors commented on previous versions of the manuscript. All authors read and approved the final manuscript.

Funding The production of this article was funded by the European Union's Horizon 2020 Research and Innovation programme under grant agreement no. 776866 for the research project RECONECT.

Data Availability Data and material are available upon request to the corresponding author.

\section{Declarations}

\section{Conflicts of Interest/Competing Interest None.}

Open Access This article is licensed under a Creative Commons Attribution 4.0 International License, which permits use, sharing, adaptation, distribution and reproduction in any medium or format, as long as you give appropriate credit to the original author(s) and the source, provide a link to the Creative Commons licence, and indicate if changes were made. The images or other third party material in this article are included in the article's Creative Commons licence, unless indicated otherwise in a credit line to the material. If material is not included in the article's Creative Commons licence and your intended use is not permitted by statutory regulation or exceeds the permitted use, you will need to obtain permission directly from the copyright holder. To view a copy of this licence, visit http://creativecommons.org/licenses/by/4.0/.

\section{References}

Alves A, Gersonius B, Kapelan Z, Vojinovic Z, Sanchez A (2019a) Assessing the co-benefits of green-blue-grey infrastructure for sustainable urban flood risk management. J Environ Manag 239(December 2018):244 254. https://doi.org/10.1016/j.jenvman.2019.03.036

Alves A, Vojinovic Z, Kapelan Z, Sanchez A, Gersonius B (2019b) Exploring trade-offs among the multiple benefits of green-blue-grey infrastructure for urban flood mitigation. Sci Total Environ. https://doi.org/10. 1016/j.scitotenv.2019.134980

Babić-Mladenović M, Kolarov V (2016) River basin studies as a basis for flood risk management planning: the Kolubara river basin case study. Water Res Manag 6:3-9 
Bach PM, McCarthy DT, Urich C et al (2013) A planning algorithm for quantifying decentralised water management opportunities in urban environments. Water Sci Technol 68:1857-1865. https://doi.org/10. 2166/wst.2013.437

Backhaus A, Fryd O (2012) Analyzing the first loop design process for large-scale sustainable urban drainage system retrofits in Copenhagen, Denmark. Environ Plan B Plan Des. https://doi.org/10.1068/b37088

Cohen-Shacham E, Walters G, Janzen C, Maginnis C (2016) Nature-based solutions to address global societal challenges. IUCN Commission on Ecosystem Management (CEM) and IUCN World Commission on Protected Areas (WCPA), Gland

Debele SE, Kumar P, Sahani J et al (2019) Nature-based solutions for hydro-meteorological hazards: Revised concepts, classification schemes and databases. Environ Res 179:108799. https://doi.org/10.1016/j.envres. 2019.108799

Demesouka OE, Vavatsikos AP, Anagnostopoulos KP (2013) Suitability analysis for siting MSW landfills and its multicriteria spatial decision support system: Method, implementation and case study. Waste Manag. https://doi.org/10.1016/j.wasman.2013.01.030

EEA (2014) EU-DEM statistical validation. Copenhagen, Denmark

EEA (2017) Climate change, impacts and vulnerability in Europe 2016- An indicator-based report. Copenhagen, Denmark

EPA (2018) Best Management Practices (BMPs) Siting Tool. https://www.epa.gov/water-research/bestmanagement-practices-bmps-siting-tool. Accessed 28 May 2020

European Commision (2015) Towards an EU research and innovation policy agenda for nature-based solutions \& re-naturing cities. European Commission, Brussels. https://doi.org/10.2777/479582

Faivre N, Sgobbi A, Happaerts S et al (2018) Translating the Sendai Framework into action: The EU approach to ecosystem-based disaster risk reduction. Int J Disaster Risk Reduct 32:4-10. https://doi.org/10.1016/j.ijdrr. 2017.12.015

FISRWG (1998) Stream corridor restoration: Principles, processes, and practices. USDA, US

Füssel H-M, Jol A, Kurnik B, Hemming D (2012) Climate change, impacts and vulnerability in Europe 2012: an indicator-based report

Government of the Republic of Serbia (2014) Serbia floods 2014. Belgrade, Serbia

Guerrero P, Haase D, Albert C (2018) Locating spatial opportunities for nature-based solutions: A river landscape application. Water 10:1-15. https://doi.org/10.3390/w10121869

IPCC (2014) Climate Change 2014: Synthesis Report. Contribution of Working Groups I, II and III to the Fifth Assessment Report of the Intergovernmental Panel on Climate Change

Jerzy Z, Lukasz S, Anna Z, Kornelia K, Maksym B (2020) Water retention in nature-based solutionsassessment of potential economic effects for local social groups. Water 12(12). https://doi.org/10.3390/ w12123347

Kuller M, Bach PM, Ramirez-Lovering D, Deletic A (2017) Framing water sensitive urban design as part of the urban form: A critical review of tools for best planning practice. Environ Model Softw 96:265-282. https:// doi.org/10.1016/j.envsoft.2017.07.003

Kuller M, Bach PM, Roberts S et al (2019) A planning-support tool for spatial suitability assessment of green urban stormwater infrastructure. Sci Total Environ 686:856-868. https://doi.org/10.1016/j.scitotenv.2019. 06.051

Lee JG, Selvakumar A, Alvi K et al (2012) A watershed-scale design optimization model for stormwater best management practices. Environ Model Softw 37:6-18. https://doi.org/10.1016/j.envsoft.2012.04.011

Lee ES, Lee DK, Kim SH, Lee KC (2018) Design strategies to reduce surface water flooding in a historical district. J Flood Risk Manag. https://doi.org/10.1111/jfr3.12268

Lehner B, Döll P, Alcamo J et al (2006) Estimating the impact of global change on flood and drought risks in Europe: A continental, integrated analysis. Clim Change. https://doi.org/10.1007/s10584-006-6338-4

Maes J, Jacobs S (2017) Nature-based solutions for Europe's sustainable development. Conserv Lett 10:121124. https://doi.org/10.1111/conl.12216

Malczewski J, Rinner C (2015) Multicriteria decision analysis in geographic information science. Anal Methods. https://doi.org/10.1007/978-3-540-74757-4

Martin-Mikle CJ, de Beurs KM, Julian JP, Mayer PM (2015) Identifying priority sites for low impact development (LID) in a mixed-use watershed. Landsc Urban Plan. https://doi.org/10.1016/j.landurbplan. 2015.04 .002

Meerow S, Newell JP (2017) Spatial planning for multifunctional green infrastructure: Growing resilience in Detroit. Landsc Urban Plan 159:62-75. https://doi.org/10.1016/j.landurbplan.2016.10.005

Plavšić J, Vladiković D, Despotović J (2014) Floods in the Sava River Basin in May 2014. In: Mediterranean Meeting on Monitoring, modelling, early warning of extreme events triggered by heavy rainfall 
Ruangpan L, Vojinovic Z, Di Sabatino S et al (2020) Nature-based solutions for hydro-meteorological risk reduction: a state-of-the-art review of the research area. Nat Hazards Earth Syst Sci 20:243-270. https://oi. org/10.5194/nhess-20-243-2020

Sarkar D, Mondal P (2020) Flood vulnerability mapping using frequency ratio (FR) model: a case study on Kulik river basin, Indo-Bangladesh Barind region. Appl Water Sci 10:17. https://doi.org/10.1007/s13201-019$1102-\mathrm{X}$

SEPA (2014) Serbia floods 2014. Ministry of Environmental Protection, Belgrade

van de Ven FHM, Snep RPH, Koole S et al (2016) Adaptation planning support toolbox: Measurable performance information based tools for co-creation of resilient, ecosystem-based urban plans with urban designers, decision-makers and stakeholders. Environ Sci Policy 66:427-436. https://doi.org/10.1016/j. envsci.2016.06.010

Viavattene C, Ellis JB (2013) Sustainable Urban Drainage System Modeling for Managing Urban Surface Water Flood Risk. Clean Soil Air Water 42(2):153-159. https://doi.org/10.1002/clen.201300225

Voskamp IM, Van de Ven FHM (2015) Planning support system for climate adaptation: Composing effective sets of blue-green measures to reduce urban vulnerability to extreme weather events. Build Environ 83:159167. https://doi.org/10.1016/j.buildenv.2014.07.018

Publisher's Note Springer Nature remains neutral with regard to jurisdictional claims in published maps and institutional affiliations. 